\title{
A Qualitative Assessment of Gender Roles and Implications for Child Nutrition in Central Malawi
}

Elizabeth Mkandawire ( $\nabla$ elizabeth.mkandawire@up.ac.za )

University of Pretoria

Clement Bisai

CARE Malawi

Elizabeth Dyke

CARE Malawi

Anne Dressel

University of Wisconsin-Milwaukee

Hazel Kantayeni

CARE Malawi

Billy Molosoni

CARE Malawi

Peninnah M Kako

University of Wisconsin-Milwaukee

Kaboni Gondwe

University of Wisconsin-Milwaukee

Lucy Mkandawire-Valhmu

University of Wisconsin-Milwaukee

\section{Research Article}

Keywords: Child Nutrition, Food Security, Inequalities, Care-Giving, Low-Income Countries, Focus Group

Posted Date: November 12th, 2021

DOl: https://doi.org/10.21203/rs.3.rs-1026200/v1

License: (c) (i) This work is licensed under a Creative Commons Attribution 4.0 International License.

Read Full License 


\section{Abstract}

Child malnutrition persists globally. While progress in reducing stunting has been witnessed over the last six years, this progress is not sufficient to meet Sustainable Development Goal targets on stunting. In Africa, child malnutrition is estimated to result in between 1.6 to $16 \%$ losses in gross domestic product. Undernutrition is also attributed as a cause of death for $11 \%$ of African children aged five years and below. Men and women play distinct roles in supporting a child's nutrition. Women frequently carry the bulk of the workload related to food, care, and health, all of which are critical factors in child nutrition. Using focus group discussions and individual interviews with communities in rural Central Malawi, we sought to understand the roles played by men and women in achieving child nutrition in this qualitative study. We found that both men and women were involved in productive, reproductive, and community work. However, consistent with the literature, women carried a disproportionate workload in supporting child nutrition compared to men. Women's heavier workloads often prevented them from being able to meet children's food needs. Nevertheless, shifts in gender roles were observed in some of the sampled communities, with men taking up responsibilities that have been typically associated with women. This undoing of gender roles did not necessarily increase women's power within the household. Improving gender equality and child nutrition will require efforts to redistribute gendered work and encourage men to move towards shared power over household decision-making and control over income with women.

\section{Introduction}

Child malnutrition is a persistent problem globally, even though child stunting has reduced by $10 \%$ over the past six years. The rate of progress is, however, not sufficient to meet Sustainable Development Goal 2 targets on reducing stunting by $40 \%$ by 2025 . Children's nutrition is a fundamental human right, but it also has implications for economic growth (1). Child malnutrition has significant implications on children's capacity to meet their future potential. In Africa, child malnutrition is estimated to result in between 1.6 to $16 \%$ losses in gross domestic product. Undernutrition is also attributed as a cause of death for $11 \%$ of African children aged five years and below (2).

The UNICEF conceptual framework, particularly the underlying causes of malnutrition, provide the framing for this paper. The framework presented in Figure 1 below defines food security as "...when all people at all times have physical and economic access to sufficient, safe and nutritious food to meet their dietary needs and food preferences for an active and healthy life" (3): 5). Care is defined as adequate care for women and children, including feeding practices. Health, in relation to the UNICEF framework specifically, is defined as access to adequate healthcare services and a healthy household environment (4).

\section{Gender roles and food security}

Men and women are expected to play diverse roles in household food security, typically informed by gender norms. Gender norms are behaviours, roles, and responsibilities that are socially allocated to men 
and women based on their sex. Gender norms also inform how men and women interact with one another (5). These roles contribute to child nutrition in various ways. According to the UNICEF conceptual framework on malnutrition, inadequate access to food, inadequate care for children and women, and insufficient health services, and an unhealthy environment are underlying causes of child malnutrition (4). These factors, particularly maternal and child care, are significantly gendered, with women carrying the majority of responsibility for childcare. However, women's multiple roles in the household place a significant burden on their ability to provide optimal care for children and source food while also ensuring a healthy household environment. Policies and programmes that target women for nutrition interventions also increase women's work burden (6). Rao et al.(7) argue that it is crucial to understand how gendered time use affects nutrition outcomes.

Globally, women contribute to children's nutrition in two ways. The first is through productive work, which includes farming and generating income to purchase food. These activities directly contribute to household food security. The second is through reproductive work, which is often unpaid and consequently considered less valuable(8). Reproductive work entails multiple responsibilities which support household food security, including cooking, processing food, drawing water, cleaning, and collecting firewood (9). These activities are undervalued because while they typically support child nutrition, they are not considered direct food production activities $(7,10)$.

Historically, women's productive and reproductive work has been heavier than men's (10-12). Childcare has been a responsibility taken up by wives, older children, and female relatives. Time-use studies frequently underestimate women's time spent on care activities because they rarely account for simultaneous tasks taking place. In many studies, women do not mention childcare as one of their duties unless prompted (13). In one study conducted in Northern Malawi, Lentz et al. (13) explained how one woman described the previous day's farming activities. When asked where her child was during this time, she responded, "With me, of course. I carry her on my back" (13): 318). In this way, childcare was rendered invisible. If this participant were asked in a survey how her time was spent, she would likely say that she was farming, discounting the fact that at the same time, she was also caring for her child.

Access to clean water has implications for food security, health and sanitation, and ultimately, the health of the household environment. The collection of water is highly feminised across Sub-Saharan Africa (14). Water is used for domestic and economic purposes, including cleaning, cooking, caring for children, and tending to small-scale agriculture(15). With only $50 \%$ of households having access to improved potable or proximal water sources(16), collecting water significantly burdens women and children who bear the primary responsibility for drawing water. As women and adolescent girls go back and forth collecting water, they spend a significant amount of time on this activity (17). For example, $40 \%$ of rural households in Malawi do not have water on the premises and walk at least 30 minutes to a water source (18). While collecting water is a necessity, the time spent on this activity has significant opportunity costs for women(19). Drawing water adds to the burden of women's unpaid domestic responsibilities, decreasing the time they could spend on income-generating and other non-essential activities such as leisure (20). 
Men's involvement has been considered a primary tool for transforming gender norms and working towards equality in terms of unpaid care work. Efforts to promote men's shared responsibility for the family are driven by the need to redistribute reproductive work equally between men and women (21). Target 5.4 of sustainable development goal (SDG) 5 emphasises promoting shared family responsibility (22). Evidence suggests that gender roles, particularly childcare and nutrition, are being challenged in Malawi, with men beginning to participate in these activities $(23,24)$. However, the extent to which men actively participate in childcare and nutrition has not been widely investigated.

While Malawian men play a vital role in providing women with finances to access healthcare services, including providing money for transport, they rarely offer any other forms of support $(25,26)$. Many programmes targeting men's involvement in pregnancy and childbirth have faced resistance from both men and women of reproductive age $(23,27,28)$. Men are uncomfortable entering spaces that are reserved for women. Social structures and ways of knowing reinforce the notion that men do not belong at prenatal visits or in labour wards, for example (25). On the other hand, women feel that they will lose control of this space that was previously their domain (28). Our paper focuses less on access to health care services and more on women's role in providing a healthy household environment.

Many scholars $(7,13,29)$ highlight that women have multiple roles to play. These roles significantly influence their capacity to provide optimal care for children. Women's disproportionate burden of productive and reproductive work appears to have remained the same over time in Malawi. In 2016, women's time spent on unpaid care work was six times higher than men's (Ministry of Finance, Economic Planning and Development (30). There is a paucity of literature highlighting men and women's roles in food, care, and health and the impact these roles have on child nutrition. The limited literature generally focused on one of the three underlying causes in the red circles in Figure 1 without exploring how gender roles in these three areas combined could affect child nutrition $(8,9,12,23,27,31)$. In low-income countries, gender norms frequently mean that women carry the bulk of responsibility for all three activities.

Though Malawian men have become increasingly involved in children's nutrition by supporting pregnant women to access nutritious food, preparing food, and participating in child care, amongst other activities, they still face barriers to participation (27). These barriers include lack of a definitive role for men to play in nutrition, time constraints, inadequate healthcare facilities to accommodate men, gender norms, and stigmatisation $(32,33)$. This paper highlights how gendered roles of men and women contribute or constrain child nutrition, based on interviews with four communities in rural Malawi. This analysis is juxtaposed with an understanding of men's roles in child nutrition, identifying opportunities for enhancing cooperation and collaboration in supporting child nutrition and gender equality simultaneously.

\section{Methods}

\section{Research context}


This study was part of a baseline study conducted in 2017 as part of the CARE Southern Africa Nutrition Initiative (SANI), a project undertaken with the financial support of the Government of Canada through Global Affairs Canada. The SANI project aims to improve the persistent poor nutritional outcomes for women and children under five years of age in the Southern African countries of Malawi, Mozambique, and Zambia. The qualitative research assessment presented here, specifically conducted in Malawi, aimed to simultaneously identify opportunities and modalities of improving gender equality, food security, and nutrition.

Between 2010 and 2015, Malawi made significant progress in reducing child malnutrition from $47 \%$ to $37 \%$ respectively $((18,34)$. Nonetheless, child malnutrition, especially undernutrition, remains a significant challenge, with only $8 \%$ of children meeting the minimum acceptable diet (MAD). MAD refers to the number of children accessing food from at least four food groups and also measures the minimum meal frequency. Limited dietary diversity means that the majority of Malawian children are not accessing diverse foods to meet their daily dietary requirements. The 2020 Global Nutrition Report indicates that while Malawi is on track to meet the global targets for maintaining a low rate of overweight and wasting in children under five, it is not projected to meet other child nutrition targets (35).

The study took place in the Dowa and Ntchisi districts of rural Central Malawi, which is predominantly matrilineal. Four traditional authorities were sampled, including Dzoole, Kalumo, Kasakula, and Kayembe. Children's nutrition in these districts was equal to or worse than the national average. Table 1 provides data from two districts on stunting, wasting, undernutrition, anaemia in children, and MAD. The data only reflects malnutrition in children under five years of age.

\section{Table 1: Child nutrition in Dowa and Ntchisi}

\begin{tabular}{|llllll|}
\hline Town & Stunting & Wasting & Undernutrition & Anaemia in children & MAD \\
\hline Dowa & $37 \%$ & $2 \%$ & $9 \%$ & $57 \%$ & $10 \%$ \\
\hline Ntchisi & $40 \%$ & $2 \%$ & $11 \%$ & $56 \%$ & $7 \%$ \\
\hline
\end{tabular}

Source: NSO and Macro, 2017

\section{Focus group discussions and individual interviews}

Data were collected from four different sub-samples of participants from one family unit. The subsamples included 1) childbearing women with at least one child under five years of age; 2) men currently living with a female partner who also had at least one child under five years of age; 3 ) mothers-in-law of the women participants interviewed, and 4) community/religious leaders. The first three sub-samples were interviewed through focus group interviews, while the community/religious leaders were interviewed through in-depth individual interviews. 
Seventy-six participants were sampled, including 19 men and 57 women. All participants were above 18 years of age. Twelve focus group discussions (FGDs) were conducted with men, women, and mothers-inlaw from the four traditional authorities. Four individual interviews were conducted with traditional leaders in each traditional authority. All participants were recruited by CARE staff who visited the research site several days before data collection. Study participants were conveniently sampled directly from the community, with assistance from community leaders.

Two interviews were conducted closer to the trading centre, and two were further away from the trading centre. The selection of these two sites was based on the assumption that behaviours and perhaps even knowledge and potentially community cohesiveness would be different based on proximity to the trading centre. All interviews with the participants took place in a private space identified by the community, including churches, schools, or quiet spaces in the community.

Before each interview, written informed consent was obtained from all participants after verbally explaining the purpose of the study. The majority of the participants provided a thumbprint as evidence of consent to participate in the study because of limited formal education. Participants were assured of confidentiality and anonymity. They were also informed of the right to withdraw from the study at any time without penalty. During the focus group interviews, pseudonyms were used in the form of numbers to maintain participant anonymity. Participants thus addressed each other by number as opposed to by name throughout the focus group interviews.

\section{Research team}

The research team consisted of a qualitative research expert who trained three research assistants/facilitators to collect the qualitative data. The first three sub-samples were interviewed through focus group interviews, while the community/religious leaders were interviewed through in-depth individual interviews. Two male research assistants conducted FGDs with men. The two alternated facilitating and taking notes during the focus group interviews. The FGDs with women and the mothersin-law were conducted by one of the female co-authors.

\section{Data and analysis}

Data were collected over several weeks in July and August 2017. FGDs included four to eight participants with all of the focus group interviews with childbearing women involving eight participants. Interviews lasted approximately one to two hours and were recorded using a digital recorder. The interviews were transcribed first in Chichewa and then translated into English by the bilingual research assistants.

The data were uploaded into Atlas.ti software. Data were iteratively coded and analysed using inductive qualitative analysis techniques. The first author reviewed all of the data and identified themes related to gender, food security, and nutrition using a thematic network approach (36). The codes were then reviewed to determine themes and sub-themes. Owing to the amount of data on gender, food security, and nutrition, the data were organised into themes that could be best presented in two separate 
manuscripts. This first manuscript focuses on the gender roles that constrain or support child nutrition as articulated by the participants. A focus on the gender constraints to achieving food security and nutrition is beyond this current manuscript's scope and will be further explored elsewhere.

The data were subjected to multiple readings by three authors. In these readings, particular attention was paid to the different roles men and women played in meeting the household's food, care, and health needs in ensuring child nutrition. Again, this was an iterative process, which sometimes led to revising categorisation of themes and sub-themes.

Throughout the process, these analyses were discussed and confirmed with the other authors, particularly the authors who conducted the fieldwork. The manuscript was also shared with CARE Malawi staff members who verified the accuracy of information related to the organisation and the related experiences of gender roles, food security, and nutrition in Malawi based on CARE's ongoing work in the communities.

\section{Limitations}

In this paper, we use the term child nutrition loosely. While the underlying causes leading to child nutrition/malnutrition (UNICEF conceptual framework) are analysed using a gender lens, the nutrient content of food is not assessed. Therefore, while the paper mentions child nutrition, this term is only used to capture how the underlying factors of the UNICEF conceptual framework are gendered and could lead to or hinder child nutrition/malnutrition.

\section{Results}

Generally, men and women play different roles in child nutrition. Table 2 lists activities that are performed by men and women. Both men and women expressed perceptions of whose responsibility each listed activity was. Five main themes were identified. The first was productive work, which was defined as activities men and women participated in to obtain food. The second was reproductive work, which included housework and care work. Leisure, gender barriers to nutrition and undoing gender roles were the three additional themes that were identified.

Eleven activities (sub-themes) were identified under the first three main themes. These activities are listed in the second column of Table 2. Men's roles were mainly associated with four activities. These included business, household labour (physical), leisure, and sourcing food. Women's roles, on the other hand, were associated with nine activities. Some men's participation in other activities was constrained by social norms that were determined by how they grew up (socialisation). Men's participation in these activities was exacerbated by barriers they faced when performing work typically associated with women.

\section{Table 2: Summary of themes and sub-themes}


Themes

Productive work: Activities to obtain food

\begin{tabular}{ll} 
& Business \\
\cline { 2 - 2 } & Sourcing food \\
\hline Housework and care work & Farming \\
\hline & Childcare \\
\cline { 2 - 2 } & Cooking \\
\cline { 2 - 2 } & Drawing water \\
\hline Leisure & Cleaning and other housework \\
\hline Gender barriers to food security and nutrition & Household repairs and construction work \\
\hline & - \\
\hline Undoing gender roles & Barriers to men's participation in "women's work" \\
\hline & Socialisation \\
\hline & - \\
\hline
\end{tabular}

\section{Productive work: Activities to obtain food}

Men and women were involved in five main activities to obtain food. These included ganyu labour, business, sourcing food and farming. While both men and women are involved in ganyu labour, this activity was excluded because the depth of data on this activity demanded a separate manuscript.

\section{Business}

More men than women mentioned involvement in business activities. Some men said that they had their own businesses. Some were involved in tin pail making. These tin pails were used for drawing water. Others sold goods and were involved in carpentry. These activities generated income which could be used for food purchases. One woman in a FGD said of the pail making business, "From this pail, you are able to find money for purchasing food." - P2

Men who owned businesses invested much of their time and effort in business-related activities. Women's role in business was only mentioned in one FGD. Women felt that business was an opportunity to generate income for food, especially when food was scarce. One woman in a FGD in 
Kasakula said, "When the woman sees that things are really hard in the home, she tries to find some money so that she can start a business." - P1

\section{Sourcing food}

Sourcing food was mainly considered as men's responsibility. While many of the income-generating activities were to source food for the household, sourcing food is highlighted as a separate theme because participants emphasised the primary role of men in this specific activity. Much of men's time was spent sourcing food by participating in ganyu labour, farming, or hunting for mice[1]. While both men and women expressed this sentiment, more men felt that sourcing food was their responsibility. Men were expected to use their income to buy food. In one FGD with men, participants were asked whose responsibility it was to buy relish[2] and other food items. There was a general consensus that this was a man's responsibility. While some participants suggested that sourcing food is both men's and women's responsibility, one man, for example, said,

"But largely it is the man who has that responsibility." - P1

Some of the items that participants mentioned that men bought included fish, meat, vegetables, maise, and sugar. For example, one woman in a focus group discussion in Kayembe said, "The man sources relish and brings it like small fish, maybe meat." - P8

Another man in a FGD in Dzoole said,

"The role of the man in the home is that he should source food in the home so that it is available, there should be good nutrition." - P3

It was only in two cases where women mentioned that they were solely responsible for sourcing food. In these cases, both women were widowed. Some women felt that it was the responsibility of both men and women to source food. One woman from Kayembe said, "In terms of sourcing food for the home, we source together. Whether it's ganyu, then it means we do the ganyu together with the man." - P1

A religious leader in Kalumo in an individual interview shared, "Eee, in the home, if there is no food, then it means it's both of them (man and woman) who take responsibility for doing ganyu, both men and women indeed. Where there is lack of food, then the man wakes up early to look (for food). The woman too wakes up early to look (for food). It is the job of everyone to source food, not just the man."

Men and women could source food in four ways, either by farming, finding ganyu labour or participating in business. One woman in a FGD in Kalumo said, "For me, if I have gone out to ask for ganyu because we don't have flour but then he also went elsewhere to look, but he didn't find it. I tell him that I have found it and I show him the basin of flour. Then I ask him to go and help me. Then where I have found, we take our hoes and go and work together. We do work together." - P3

\section{Farming}


Both men and women shared that they had a role to play in farming. Although more women than men expressed this joint role, both men and women described situations where they participated in some form of farm work. One woman from Kalumo said, "It's the responsibility of both of us in the home. The one who starts off first in the morning is the man. I stay behind so that I can bathe the children, they should go to school. When I am finished is when I go to the garden." - P5

A man from Kayembe shared that, "In addition, we can say it's both the man and the woman. Since you mentioned about farming, both are involved with farming work, the man does not do it alone." - P2

In one FGD in Kasakula, the women joked that the rainy and ploughing seasons were a blissful time for marriage because they worked together with the men. However, when ploughing was completed, men were not as helpful. In some cases, men would leave their wives and marry another woman. One woman said, "It really happens indeed. When you are finished ploughing, that's it. You harvest, that's the end of the marriage. This is what she means when she says the wife of the rainy season. The marriage is no longer there, no." - P3

While farming was generally considered a shared responsibility, some women felt they were mainly responsible for farming. One woman from Kalumo said, "For us women to farm on our own, it's because of the laziness of the men. They refuse to go to the garden. That is why you find that we farm on our own. Yes, they are lazy." P2

Alcohol presented a significant barrier to men's participation in farming activities. One woman from Kasakula shared, "When they are drunk? Then you will go to the garden while he (she used the term "it"; icho) is just there sleeping." - P7

Another woman in the same FGD said, "But also, when he is extremely drunk, in the morning, he wakes up with no strength at all. So, you just pick up your hoe, and you go to the garden, there you plough." - P5

\section{Housework}

Housework entailed five activities, including childcare, cooking, household labour, drawing water, and cleaning.

\section{Childcare}

Although it was reported that both men and women participated in childcare, this was mainly considered women's responsibility. No men reported solely being responsible for this activity. Childcare, as women's responsibility, was expressed mainly by men. Activities related to childcare included feeding (including breastfeeding) and bathing children, washing diapers, preparing food for children, washing baby clothes, and putting children to bed. One man from in a FGD in Kalumo said,

"It is different because when it comes to the child, the main person is the woman because if the child is breastfeeding, if you take him, then it means they will cry and will not stop soon. But when the child is 
with the mother, she will just start breastfeeding him. So, it means the main work is done by the mother." $-\mathrm{P} 3$

Both men and women felt that childcare was a woman's responsibility because women spent more time with children. When asked why only the mother could feed the child, a man from an FGD in Kalumo said, "It is often the mother who stays with the child. As a man, you are out, but the child stays with the mother." - P4

A mother in law in a FGD in Kasakula shared that, "...a man does not walk with a child but a woman. Children are for a woman because a man does not go about with children. Breastfeeding, I am the one who breastfed. So, the one who goes about with children will pick up the hoe and go and do ganyu because she is the one who knows about the needs of a child." - P1

Both men and women mentioned that men also play a role in childcare. Both men and women felt that men do and are capable of being involved in childcare. An equal number of men and women shared this sentiment. In one FGD with men in Kayembe, men were asked whose responsibility it was to care for infants. A few respondents felt that it was both men and women's responsibility. Childcare activities that both men and women participated in included: looking after the baby, cooking food for children, and bathing children. One woman in a FGD in Kayembe said, "Men who are understanding do play a role." P4

In some cases, men shared that they only became involved in childcare when the mother was busy. One man in a FGD in Kayemba shared, "We help with the baby if the mother is too busy." - P5

One man from Kayembe shared that because he had provided financial resources, he had contributed towards childcare. He said, "That is for both because if I go out and bring soap and my wife uses the soap to wash the children's clothes, it means both of us have played a role." - P1

\section{Cooking}

Similar to childcare, more men than women expressed that cooking was women's responsibility. One mother-in-law in a FGD in Kasakula said, "The women are the ones who cook. They cook on their own even if they are tired. Here, it is the women who cook. Maybe in our friends' areas, men are able to cook. But here in our area, women are the ones who cook." - P2

More women than men expressed that cooking was sometimes a shared responsibility. One woman from Kayembe said, "For me, I don't experience abuse in my marriage. He helps me...cooking, feeding the children, chopping firewood." - P2

One man from Kayembe shared that, "But for me, I am able to help in cooking. At times I can tell my wife that today you can rest, I will do this one." - P4 
The other men laughed when he shared this comment. Most men felt that cooking was still predominantly women's responsibility. However, there were certain circumstances under which men also cooked. These circumstances included when a woman was busy, ill, pregnant, or away from home. One man from Dzoole said, "There are some chores that have stayed with women. Like here, for them to find you cooking, then it means the woman is sick, or she is away from the home." - P3

A woman in a FGD in Kasakula shared, "It is us, women. We do not have the man cook, no. But when we are away, he cooks and also when we are sick is when he cooks." - P1

\section{Drawing water}

Both men and women felt that drawing water was women's responsibility. No men reported participation in collecting water. Women shared that water could be collected up to three times a day. This water was used for cooking, washing clothes, bathing, and washing dishes. One woman said, "Maybe the water she drew in the morning is finished, she will go again to draw more water from the well." - P1

Sometimes children helped women to collect water, which eased the workload of women. Even pregnant women were expected to collect water. In some cases, mothers-in-law helped when a woman was further along in her pregnancy. One woman in a FGD in Kasakula shared, "Women who are expecting fetch water a lot. If there are children, they help her. But for those who do not have children, the mother-in-law can also help when they see that the woman is very tired (with pregnancy)." - P1

\section{Cleaning and other housework}

More men than women felt that housework was women's responsibility. Housework included: sweeping, washing dishes, collecting firewood, going to the maize mill, and washing clothes. One man in a FGD in Kayembe said, "She must clean the house when she wakes up, clean the plates, prepare porridge for the baby and for everyone then thereafter go farming." - P2

A woman in a FGD in Kayembe said, "In the afternoon, the man goes to chat. Then I continue with the work. I should wash the dishes, put them in their place where they go. If there is something else that needs to be done, I do that, whether it's washing, I should wash if that day things were not washed. I should also sweep the house after we have eaten nsima[3]." - P1

Some men and women shared that housework is the responsibility of both sexes. Again, there were certain circumstances under which men participated in housework. One woman from Kayembe said, "That is how I see it. When I am expecting, he helps me cook, chop firewood, even going to the mill." $-\mathrm{P} 2$

\section{Household labour}

There are certain activities related to the physical maintenance of the home that were considered men's responsibility. These activities were mentioned in four FGDs. Both men and women felt that they could 
not perform these activities because they required physical strength. One woman said that men were responsible for, "Constructing houses. We women cannot manage." - P2

Another man in a FGD in Kayembe said, "The tasks must be different since we men do some things that women cannot do, and the women have tasks too that we can't do. If we went to farm and come back, the wife will occupy herself with cooking while will be busy constructing a tobacco shed. You can't ask the wife to construct a tobacco shed which involves digging and climbing on a roof. So our tasks are indeed different." - P1

\section{Leisure}

Men spent more time than women on leisure activities, especially when there was not much farm work to be completed. Men's leisure time activities were identified mostly by men themselves. Men's leisure activities mentioned by men and women included: chatting, playing bawo[4], drinking alcohol, playing soccer, watching sports, and resting. One man in a FGD in Kayembe said, "Because we are not usually home, we are always up and about, like we said before that we go drinking. Interacting with friends, playing soccer, meanwhile, the children are with their mothers." - P1

Women were generally unable to enjoy the same amount of leisure time because of domestic responsibilities and socially prescribed gender role expectations. One woman in a FGD in Kayembe said, "Men like going to chat more than women because you cannot go out the whole day and then the next day, the whole day, no. But for them, there is the opportunity to go to bawo. You continue your work in the home, you cannot leave. But the man goes to bawo." - P1

Women had far less leisure time than men. Women's leisure was only mentioned by a few men. Women's leisure time included: chatting with friends, going to church groups or choir, and reading the Bible. One woman from Kayembe said, "When we eat in the afternoon, we have to chat. If you go to church groups, you need to go. If there is choir, you go and return and then come and take care of your home." - P3

\section{Gendered barriers to child nutrition}

The gendered roles men and women play in food, care, and health often constrained their ability to meet children's nutrition needs. These included women facing time constraints and barriers to men performing work that is typically associated with women.

\section{Time constraints and barriers to men performing women's work}

Women's multiple roles often mean that they make trade-offs between performing their household responsibilities or sourcing food. Collecting water, discussed above, was one of the tasks that women felt was particularly time consuming. Women also shared that they could not freely pursue ganyu labour because of household responsibilities. One woman from Dzoole said, "The difference is that we are busy, so the ganyu that we do is limited. We have to first do household chores, compared to men (who don't)." P8 
Societal expectations of men often prevented them from supporting women in reducing their work burdens. Some men experienced shaming if they performed work that was associated with women. This fear of backlash prevented men from performing this work when women were home. A man from Dzoole explained that you only help with household chores when the woman is away, "But if she is there, then people will disrespect you that your wife has fed you medicine. In refusing the saying that they have fed you medicine, this is why women are suffering with these chores." - P3

These gender roles appeared to be learned through a process of socialisation from childhood and a lack of exposure to role models who did not follow traditional gender norms. One man in a FGD in Kalumo said, "The difference between this work...like us, we also observed from our parents because like in the area of cooking like this then it means our parents, they have never really been involved with this issue of gender so that some things we take it from our parents, differentiating work." - P5

Keeping things the same, as they were in the past, challenges changing gender norms. As another man from Kayembe said, "This is how it has been from the past, that a woman must cook." - P1

Mothers-in-law from Kasakula shared that their children behaved a certain way because they learnt these behaviours from their parents. One woman said, "A chick imitates what the mother hen does. She is doing it, and the child is there. You cannot say it will not see. It will see." - P1

\section{Undoing gender roles}

The results of the first three themes suggest that some activities, although considered women's responsibility, were performed to some extent by both sexes. There was an indication that men and women were subverting some of the socially prescribed traditional gender roles. When asked how this change came about, one woman from Dzoole said, "It started some years back when the issue of gender just came. They [men] actually changed." - P7

Women suggested that both men and women had an equal role to play in the home. One woman from Kayembe said, "Yes, it was different in the past. In the past, the one who was seen to be at the forefront was the man. But today, no. Everyone has their own role. The man needs to participate in whatever way will be helpful. The woman needs to participate in whatever way will be helpful." - P3

Another woman from Kayembe said, "In the past, it was different from nowadays. In the past, they said the man is the head of the family. But today, "gender" has come. Everyone has the right to play a role." P1

One woman from Kayembe mentioned that she is part of an organisation that offers education on gender. They teach the communities that there is no difference between a man and a woman and that women can also perform men's tasks. She said, "Things indeed, have changed. They are different from what it was like. Even in the home, you find that when the man is not there, and the roof is leaking, you just say, there is just need for some paper, bring a stick. And you climb up indeed, you take a paper, and you place it there. Then it means everything is well there." - P4 
A man in a FGD in Kalumo said, "It's important that when it comes to the role of cooking, we all need to play a role because there are some of us men, we just pressure women that you should go cook when perhaps the woman is also doing other work. Yet you have the opportunity, you have time that you can also take over from the woman, it doesn't mean that you will not have intelligence, no. But household chores are about helping one another, both of you want to work towards good nutrition in the home." - P5

\section{Discussion}

Literature highlights that women play a greater role in children's nutrition $(31,37-39)$. However, little is understood about women's role in relation to men's role in nutrition. Our study finds that men and women's roles in child nutrition are typically gendered, with more women participating in food, care, and health-related activities. The increased work burden women carry in meeting children's nutrition needs threatens positive child nutrition outcomes as they often have to navigate generating income versus food preparation. Our findings suggest that men could also play an essential role in children's nutrition. While this role can reduce women's work burden, men's shared responsibility in child nutrition is insufficient for overcoming the structural inequalities that undermine gender equality.

Concerning food, both men and women participated in several activities to obtain food for the household. Although more men reported owning businesses than women, there was an indication that some women were involved in business activities to generate income. Sourcing food was primarily seen as men's responsibility. However, women frequently participated in this activity too. Men also typically had more time to generate income, given women's large household burden. As such, there was an expectation that men would, or rather should, be responsible for purchasing food. This finding is consistent with literature that suggests that Malawian men are typically responsible for sourcing food $(23,24)$. The food items that men were said to buy increased the diversity of food consumed in the household. This food can significantly improve household nutrition.

Farming, also related to food, was generally perceived as both men's and women's responsibility. Marriage patterns in rural Malawi tend to be tenuous and are informed by the harvest. Some women shared that they carried the primary responsibility for farming. Alcohol and laziness were considered two of the main reasons for men's lack of participation in farming. Given the multiple responsibilities women carry, they rarely had time for leisure. On the other hand, men spent a significant amount of time on leisure, mainly when it was not a farming season. Women expressed frustration with men who did not offer adequate contributions to farming. They also raised concern that some men did not provide sufficient support financially or with household responsibilities. This finding is consistent with Kerr et al. (40), who found that women were not only concerned about lack of adequate food, they were also concerned with their partner's behaviours that worsened food insecurity.

Concerning care, men and women suggested that the children needed to be with the mother because women breastfeed. Consequently, childcare was considered women's responsibility because women spent more time with children. Men would only help with childcare under certain conditions. The same 
applied to cooking. Men would only help with cooking if women were busy, sick, or away from home. The analysis indicates that the mothers-in-law seem to hold and perpetuate expected gender roles. Women regarded a man who helped with childcare was described as understanding. Similarly, women felt that men who helped with cooking were not abusive, reinforcing the idea that these were still women's responsibilities. This finding is consistent with Pierrioti et al. (41), who suggest that the notion that men were "helping" reinforces the belief that specific roles are reserved for women and others for men. While significant changes may occur should such gender patterns continue to be practised over a long period, gender equality will only be realised depending on the extent to which men are willing to share household duties and relinquish some form of power and control over resources within the household.

The likelihood that women might carry out multiple activities simultaneously, especially childcare, is important to note. Women explained that they frequently went to ganyu labour with their children. When women described farming or business activities they participated in, it was unclear where the children were during this time. As Lentz et al. (13) suggest, the time spent on childcare was not necessarily captured because women were not always prompted to discuss these issues. However, women are likely performing childcare activities and farm work simultaneously, especially in cases where social support systems, such as grandmothers to look after children, are weak. However, even in cases where social support systems are available, challenges persist when a child is still breastfeeding. The fact that childcare is ignored reinforces the idea that women and men do not acknowledge the value of unpaid work, particularly care work, because it generates no income.

Drawing water, washing dishes and clothes, and cleaning the house are all activities that contribute to the household's health environment. Women mainly take up these activities. When women and men were asked if men participated in certain activities that society typically considered women's work, some women said that men had played a role by buying soap. This finding reinforces the notion that paid work is more valued. Even though the man is not actively involved in household work, he has contributed to household health because he has provided the financial resources needed to make this possible.

While some men participated in reproductive work, this was still not considered the norm. Men described women's activities very clearly. While they did not explicitly articulate that women's workloads were more cumbersome than theirs, they explained that they could not participate in these activities because it was not the norm. Societal gender norms continue to perceive women's heavy workloads as normal (12), failing to understand the underlying negative impacts these have on childcare and, ultimately, health and nutrition. Women's work burden and men's lack of participation sometimes resulted in women not preparing food or attending to other housework. Consequently, children frequently missed meals when women were not around. While some men were able to cook, most still felt that this work was reserved for women. The extent to which men prepared food for children when women were not around could have been further investigated with additional probing. However, it was clear that traditional gender roles were no longer strictly adhered to in some cases. 
Men and women indicated that some men were involved in cooking, cleaning, housework, and childcare. These activities are contrary to the traditional gender roles described in the literature $(12,31)$. Gender advocacy has made advancements, particularly when these activities are driven from within the community. However, this finding was specific to one community where programming enabled people to engage differently and to speak to issues of gender in a more informed way. This finding is not necessarily representative of the rest of the country. However, other studies from Ntcheu and Northern Malawi, with similar programming, indicate some advances in undoing traditional gender roles $(24,32$, 42). In these cases, men recognised the need to support women with housework. The support they offered could improve maternal and child nutrition. Drawing on the analysis, figure 2 illustrates how the imbalance in gender roles takes women further away from providing optimal nutrition for children and women. Levelling out these work burdens could increase men and women's capacity to support child nutrition.

A second manuscript will explore the extent to which efforts to involve men in work traditionally accepted as women's responsibility has increased women's decision-making and control over income in the household. While women's time is less constrained, and they may be able to pursue other incomegenerating activities, this may not necessarily improve their power in the household. A study by Handa et al.(43) indicates that when women's income increases, they only have increased control over their income and not necessarily the household's pooled income. Re-allocating or redistributing gender roles alone is not sufficient. As Ganle and Dery (28) point out, some women may not want men to be involved in women's work as it may threaten their autonomy. Therefore, it is essential that communities, particularly women, are engaged in processes to define how they would like to see gender norms evolve to transform social systems that underpin inequalities.

\section{Conclusions And Recommendations}

This paper suggests that traditional gender roles remain prevalent in these four Malawian communities. Women are still primarily responsible for the food, care, and health of the household. Women's heavy workloads prevent them from providing optimal care and nutrition for children. However, men do offer support when women are overburdened or away from home. The extent to which men offer this support needs to be quantitatively understood.

While efforts to advance gender equality in terms of gender roles appear to have had marginal success, the extent to which these efforts have successfully encouraged men to share power remains unclear. Men are taking on tasks that have typically been associated with women. The success of these interventions depends on women having more time to pursue income-generating activities, which may or may not increase their power within the household. Efforts to increase men's participation in "women's activities" need to be complemented with community-led processes that define how gender roles can change to improve gender power relations within the household and society at large.

\section{Declarations}




\section{Ethics approval and consent to participate}

Before starting data collection, ethical approval was obtained from the National Commission for Science and Technology. Approval was also given by the University of Wisconsin-Milwaukee (UWM) Institutional Review board for faculty and students to assist CARE staff with data analysis and writing up of findings. Before each interview, written informed consent was obtained from all participants after verbally explaining the purpose of the study. The majority of the participants provided a thumbrint as evidence of consent to participate in the study because of limited formal education. All research protocols were performed in accordance with relevant guidelines and regulations.

\section{Consent for publication}

Not applicable.

\section{Availability of data and materials}

The data is not available to be shared publicly as it could compromise the privacy of research participants, but are available from Clement Bisai at CARE Malawi on reasonable request.

\section{Competing interest}

CARE Malawi funded fieldwork for this research. Lucy Mkandawire-Valhmu was paid by CARE Malawi to conduct the research. Elizabeth Dyke was paid to design the study and to train the research assistants in data collection methods. The remaining authors have no competing interests.

\section{Funding}

No funding was provided to produce this paper.

\section{Author's contributions}

Elizabeth Mkandawire: Conceptualisation, Data analysis, Writing.

Clement Bisai: Methodology, Study design, Investigation, Writing, Data analysis.

Elizabeth Dyke: Methodology, Study design, Investigation, Writing, Data analysis.

Anne Dressel: Data Analysis and Writing.

Hazel Kantayeni: Methodology, Study design, Investigation, Writing, Data analysis.

Billy Molisoni: Methodology, Study design, Investigation, Writing, Data analysis.

Penninah M Kako: Data Analysis and Writing.

Kaboni Gondwe: Data Analysis and Writing. 
Lucy Mkandawire-Valhmu: Methodology, Investigation, Writing.

\section{Acknowledgements}

This study was part of a baseline study conducted in 2017 as part of the CARE Southern Africa Nutrition Initiative (SANI), a project undertaken with the financial support of the Government of Canada through Global Affairs Canada. A vote of thanks to Savannah Rae Ely who assisted with formatting this manuscript.

\section{Footnotes}

${ }^{1}$ Mice are a good source of protein particularly in the rural areas. Men and boys frequently hunt for and trap mice for household food.

2 Relish is eaten together with the cornmeal staple nsima, usually in the form of vegetables or beans or a protein the family can afford.

${ }^{3} \mathrm{Nsima}$ is a thick paste made of maize or corn flour that is eaten as a staple throughout Malawi and other South East African countries. It is eaten along with vegetables, beans and if available, a protein such as meat or eggs.

${ }^{4}$ Bawo is a traditional board game played in most of East Africa including Kenya, Tanzania, Comoros, Malawi, as well as some areas of DR Congo and Burundi.

\section{References}

1. UN. UN Convention on Economic Social and Cultural Rights. New York: UN; 1976.

2. AUC. Africa Agenda 2063: First ten-year Implementation Plan 2013 - 2023. Addis Ababa: AUC; 2015.

3. Security CoWF. Coming to terms with terminology. Rome; 2012.

4. UNICEF. UNICEF's approach to scaling up nutrition for mothers and children. New York; 2015.

5. Cislaghi B, Heise L. Gender norms and social norms: differences, similarities and why they matter in prevention science. Sociology of Health \& Illness. 2020;42(2):407-22.

6. Schipanski ME, MacDonald GK, Rosenzweig S, Chappell MJ, Bennett EM, Kerr RB, et al. Realizing Resilient Food Systems. BioScience. 2016;66(7):600-10.

7. Rao N, Pradhan A, Roy D. Gender Justice and Food Security in India: A review. IFPRI Discussion Paper 01600, Washington DC. Washington, DC; 2017.

8. Choudhary N, Parthasarathy D. Gender, Work and Household Food Security. Economic and Political Weekly. 2007;24(6):523-31.

9. Naz M, Khan IA, Shahbaz B. Role of rural women in agriculture and household food security in Faisalabad district.. Pakistani Journal of Agricultural Science. 2014;51(3):759-63. 
10. Doss C, Meinzen-Dick R, Quisumbing A, Theis S. Women in agriculture: Four myths. Global Food Security. 2018;16(2018):69 - 74.

11. Doss C. If women hold up half the sky, how much of the world's food do they produce? ESA Working Paper No 11-04. Rome; 2011.

12. Kerr RB. Food Security in Northern Malawi: Gender, Kinship Relations and Entitlements in Historical Context. Journal of Southern African Studies. 2005;31(1):53-74.

13. Lentz E, Bezner Kerr R, Patel R, Dakishoni L, Lupafya E. The Invisible Hand that Rocks the Cradle: On the Limits of Time Use Surveys. Development and Change. 2019;50(2):301-28.

14. Geere J, Cortobius M, editors. Who carries the weight of water? Fetching water in rural and urban areas and the implications for water security 2017.

15. Shaw S. Women's Lives around the World: A global encyclopedia. 4 ed. Shaw S, editor. Conecticut: Greenwood Publishing Group; 2018.

16. UNICEF, WHO. Progress on sanitation and drinking water - 2015 update and MDG assessment. New York: UNICEF; 2015.

17. Graham JP, Hirai M, Kim S-S. An Analysis of Water Collection Labor among Women and Children in 24 Sub-Saharan African Countries. PLOS ONE. 2016;11(6):e0155981.

18. ICF NSOaM. Malawi Demographic and Health Survey 2015 - 16. Zomba and Maryland: NSO and ICF Macro; 2017.

19. Fleifel E, Martin J, Khalid A. Gender specific vulnerabilities to water insecurity 2019 [Available from: https://ic-sd.org/wp-content/uploads/2019/11/eliana-fleifel.pdf.

20. Kayser GL, Rao N, Jose R, Raj A. Water, sanitation and hygiene: measuring gender equality and empowerment. Bulletin of the World Health Organization. 2019;97(6):438-40.

21. Morrell R, Dunkle K, Ibragimov U, Jewkes R. Fathers who care and those that don't: Men and childcare in South Africa. South African Review of Sociology. 2016;47(4):80-105.

22. (UNGA) UNGA. Transforming our world: The 2030 agenda for sustainable development. General Assembley 70 session. New York: UNGA; 2015.

23. Manda-Taylor L, Mwale D, Phiri T, Walsh A, Matthews A, Brugha R, et al. Changing times? Gender roles and relationships in maternal, newborn and child health in Malawi. BMC Pregnancy and Childbirth. 2017;17(1).

24. Mkandawire E, Hendriks SL. "The role of the man is to look for food": Lessons from men's involvement in maternal and child health programmes in rural Central Malawi. PLOS ONE. 2019;14(8):e0221623.

25. Kululanga LI, Sundby J, Chirwa EM, Malata A, Maluwa AO, editors. Barriers to husbands' involvement in maternal health care in a rural setting in Malawi: a qualitative study2012.

26. Mseu D, Nyasulu BM, Muheriwa S. Evaluation of a Safe Motherhood project in Ntcheu district, Malawi. International Journal of Womens Health. 2014;6:1045-55. 
27. Mkandawire E, Hendriks SL. A qualitative analysis of men's involvement in maternal and child health as a policy intervention in rural Central Malawi. BMC Pregnancy and Childbirth. 2018;18(1):37.

28. Ganle JK, Dery I, Manu AA, Obeng B. 'If I go with him, I can't talk with other women': Understanding women's resistance to, and acceptance of, men's involvement in maternal and child healthcare in northern Ghana. Soc Sci Med. 2016;166:195-204.

29. Akanle O, Adesina JO, Ogbimi AO. Men at work keep-off: male roles and household chores in Nigeria. Gender and Behaviour. 2016;14(3):7833-54.

30. Ministry of Finance EPaD. Malawi Growth and Development Strategy (MGDS) II Review and Country Situation Analysis Report. Lilongwe: Minitry of Finance, Economic Planning and Development, Government of Malawi; 2016.

31. Ragasa C, Aberman N-L, Alvarez Mingote C. Does providing agricultural and nutrition information to both men and women improve household food security? Evidence from Malawi. Global Food Security. 2019;20:45-59.

32. Kerr RB, Chilanga E, Nyantakyi-Frimpong H, Luginaah I, Lupafya E. Integrated agriculture programs to address malnutrition in northern Malawi. BMC Public Health. 2016;16(1).

33. Kululanga LI, Sundby J, Malata A, Chirwa E. Male involvement in maternity health care in Malawi. Afr J Reprod Health. 2012;16(1):145-57.

34. Macro NSOal. Malawi Demographic and Health Survey. Zomba and Maryland: NSO and Macro; 2010.

35. Initiatives D. Global Nutrition Report. Bristol: Development Initiatives; 2020.

36. Attride-Stirling J. Thematic networks: an analytic tool for qualitative research. Qualitative Research. 2001;1(3):385-405.

37. Abuya BA, Ciera J, Kimani-Murage E. Effect of mother's education on child's nutritional status in the slums of Nairobi. BMC Pediatrics. 2012;12(1):80.

38. Aberman N-L, Roopnaraine T. To sell or consume? Gendered household decision-making on crop production, consumption, and sale in Malawi. Food Security. 2020;12(2):433-47.

39. Smith LC, Ramakrishnan U, Ndiaye A, Haddad L, Martorell R. The importance of women's status for child nutrition in developing countries. Washington. DC: International Food Policy Research Institute; 2003.

40. Kerr RB, Lupafya E, Shumba L. Food Sovereignty, Gender and Nutrition: Perspectives from Malawi. Conference Paper \#68. New Haven: Program in Agrarian Studies, Yale University. Conference paper for discussion at: International Conference September 14-15, 2013.; 2013.

41. Pierotti RS, Lake M, Lewis C. Equality on His Terms: Doing and Undoing Gender through Men's Discussion Groups. Gender \& Society. 2018;32(4):540-62.

42. Mkandawire E, Hendriks SL. A gender assessment of Malawi's National Nutrition Policy and Strategic Plan 2007 - 2012.. Development Policy Review 2018;36 (2):0634 - 056. 
43. Handa S, Peterman A, Davis B, Stampini M. Opening Up Pandora's Box: The Effect of Gender Targeting and Conditionality on Household Spending Behavior in Mexico's Progresa Program. World Development. 2009;37(6):1129-42.

\section{Figures}

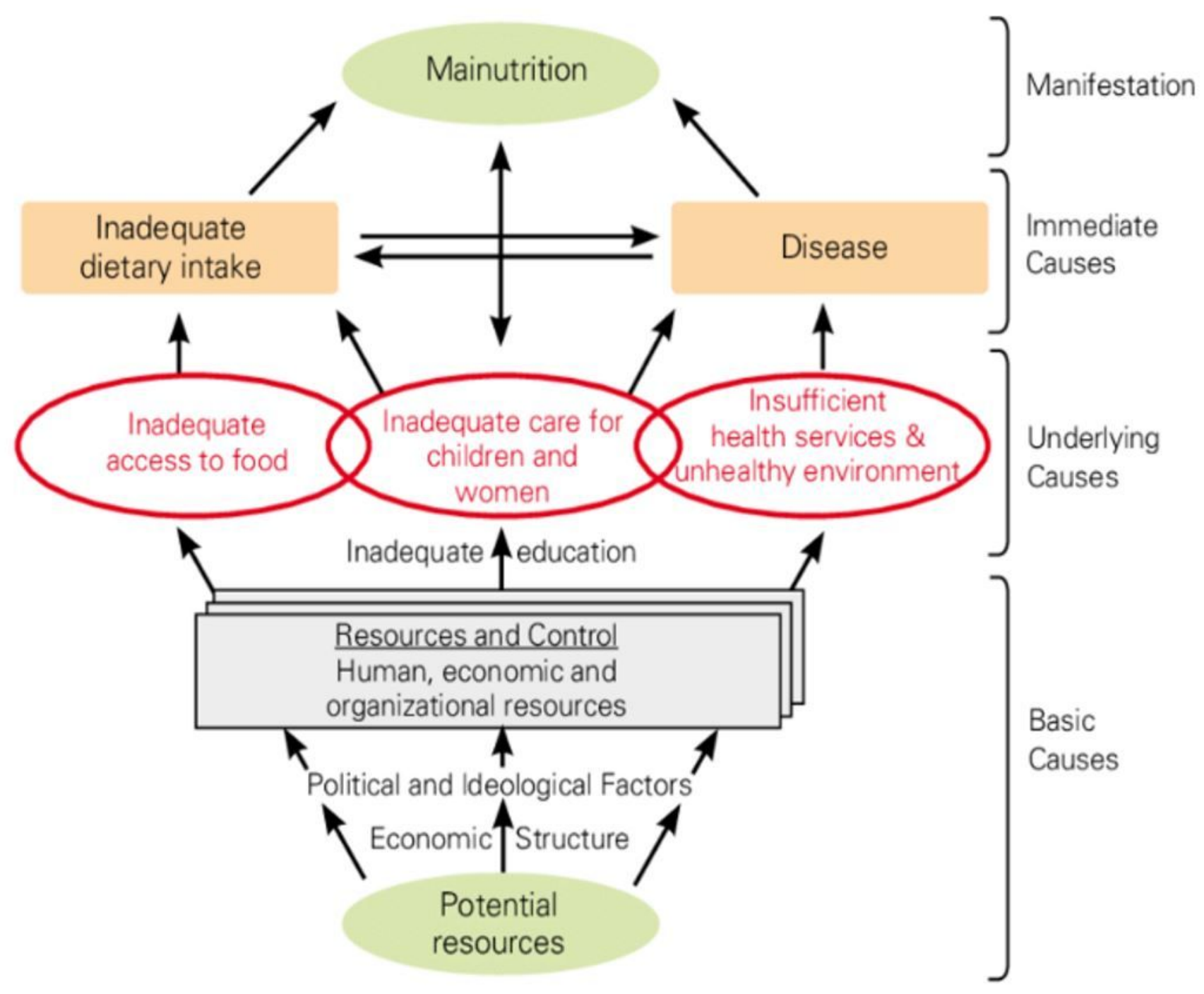

Figure 1

UNICEF Conceptual Framework of Malnutrition Source: UNICEF, 2015 


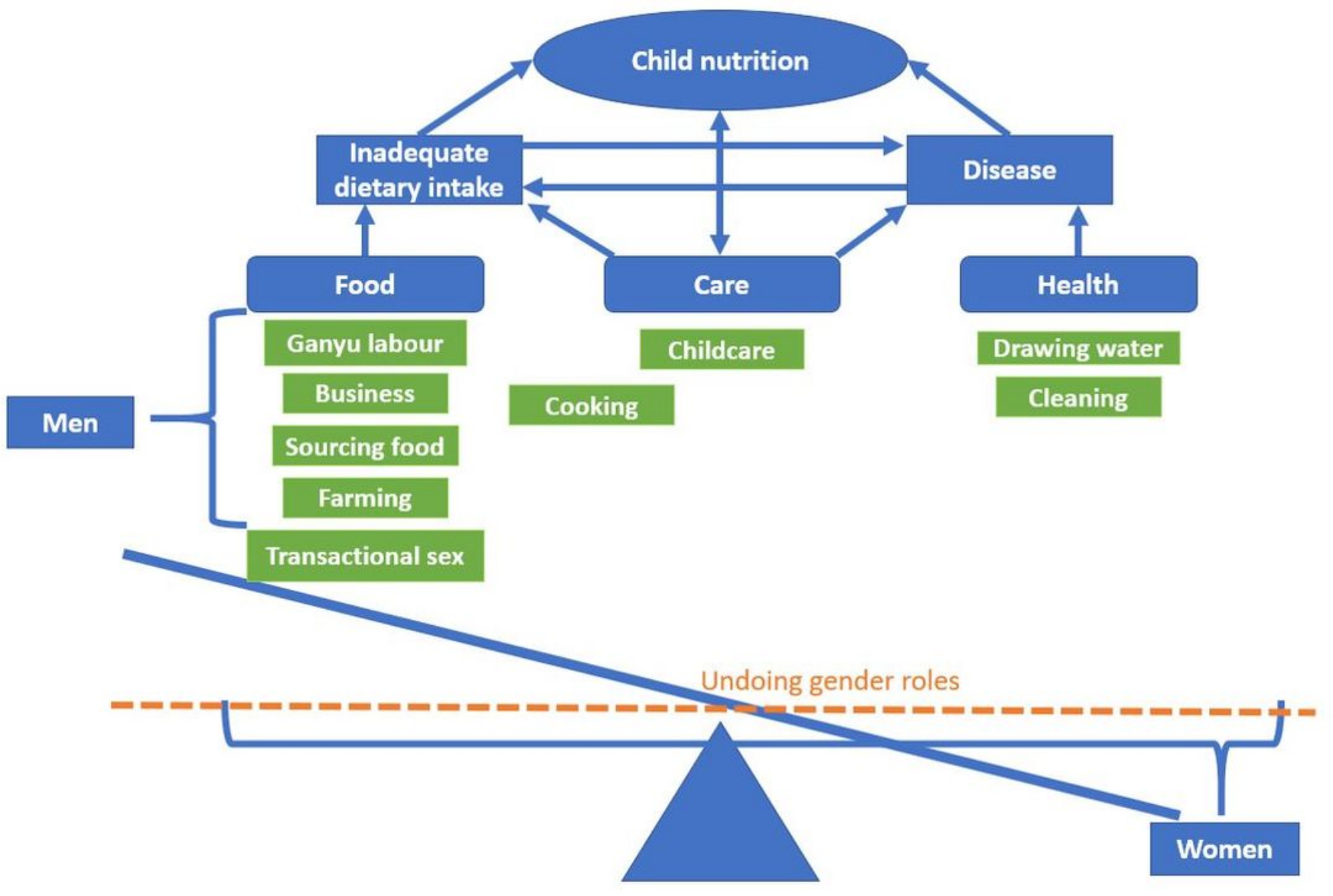

Figure 2

Women's work burden in child nutrition Source: Developed by authors 